\title{
Immunoadsorption therapy in patients with multiple sclerosis with steroid-refractory optical neuritis
}

Michael J Koziolek ${ }^{1 *}$, Desiree Tampe ${ }^{1}$, Matthias Bähr ${ }^{2}$, Hassan Dihazi ${ }^{1}$, Klaus Jung $^{3}$, Dirk Fitzner ${ }^{2}$, Reinhard Klingel ${ }^{4}$, Gerhard A Müller ${ }^{1}$ and Bernd Kitze ${ }^{2}$

\begin{abstract}
Background: In multiple sclerosis relapses refractory to intravenous corticosteroid therapy, plasma exchange is recommended. Immunoadsorption (IA) is regarded as an alternative therapy, but its efficacy and putative mechanism of action still needs to be established.

Methods: We prospectively treated 11 patients with multiple sclerosis who had optical neuritis and fulfilled the indications for apheresis therapy (Trial registration DE/CA25/00007080-00). In total, five IA treatments were performed using tryptophan-IA. Clinical activity (visual acuity, Expanded Disability Status Scale, Incapacity Status Scale), laboratory values and visual evoked potentials were measured before, during and after IA, with a follow-up of six months. Moreover, proteomic analyses were performed to analyze column-bound proteins as well as corresponding changes in patients' sera.

Results: After the third IA, we detected an improvement of vision in eight of eleven patients, whom we termed responders. Amongst these, the mean visual acuity improved from $0.15 \pm 0.12$ at baseline to $0.47 \pm 0.32$ after the third IA $(P=0.0252)$ up to $0.89 \pm 0.15(P<0.0001)$ at day $180 \pm 10$ after IA. Soluble interleukin-2 receptor decreased in responders $(P=0.03)$, whereas in non-responders it did not. Proteomic analyses of proteins adsorbed to IA columns revealed that several significant immunological proteins as well as central nervous system protein fragments, including myelin basic protein, had been removed by IA.

Conclusions: IA was effective in the treatment of corticosteroid-refractory optic neuritis. IA influenced the humoral immune response. Strikingly, however, we found strong evidence that demyelination products and immunological mediators were also cleared from plasma by IA.
\end{abstract}

Keywords: Apheresis, Autoimmune diseases, Evoked potentials/visual, Immunoadsorption, Multiple sclerosis, Optic neuritis, Proteomics

\section{Background}

Previous studies have described four immunopathological patterns of demyelination in early multiple sclerosis (MS) lesions, with pattern II being characterized by antibody and/or complement-associated demyelination [1]. Several specific antibodies have been described and discussed to contribute to the humoral autoimmune response in MS [2]. Immunoglobulins are synthesized intrathecally;

\footnotetext{
* Correspondence: mkoziolek@med.uni-goettingen.de

${ }^{1}$ Department of Nephrology and Rheumatology, Georg-August-University

Göttingen, Robert-Koch-Strasse 40, D-37075 Göttingen, Germany

Full list of author information is available at the end of the article
}

however, at least part of the humoral response in MS is derived systemically from the blood [3].

Therapeutic plasma exchange (PE) is based on the separation of plasma from cellular blood components, allowing the removal of substances up to a molecular weight of $3 \times 10^{3} \mathrm{kDa}$. As shown in a randomized placebo controlled cross-over study, PE was efficient for steroid - refractory relapses in about $40 \%$ to $50 \%$ of cases of acute central nervous system inflammatory demyelinating diseases [4]. The usefulness of PE has also been extended to severe optic neuritis in patients with MS $[5,6]$. Thus, the use of $\mathrm{PE}$ in steroid-refractory relapses has become an integral 
part of European guidelines for the treatment of MS [7]. Clinical-pathological correlation analyses have shown that all patients with pattern II pathology but none with pattern I or pattern III experienced improvement in neurological deficits after being treated with PE [8]. This selective response suggests a removal of pathogenic humoral and plasma factors by PE.

Immunoadsorption (IA) provides a more selective approach and the potential for technical innovations in therapeutic apheresis techniques, allowing the elimination of pathogenic antibodies while sparing other plasma proteins. With IA, relevant side effects of $\mathrm{PE}$ resulting from protein substitution can be avoided [9]. We hypothesized that IA is at least equally efficient compared to PE as an escalation therapy for steroid-unresponsive relapses of MS. Therefore, we performed a prospective trial to compare IA treatment in 11 patients with MS with our earlier patient population treated with PE for their MS [10]. In addition, proteomic analyses of column-bound proteins were performed as well as measurements of corresponding changes in patients' plasma samples.

\section{Methods}

\section{Patients}

We prospectively included 11 consecutive patients with MS who had functionally disabling acute optical neuritis. Patients fulfilled the indications for apheresis treatment due to this steroid-unresponsive MS relapse according to German guidelines (http://www.dgn.org) [7].

The study protocol had been approved by the local ethics committee prior to study initiation (no. 2/4/07) and registered at the local government (no. DE/CA25/ 00007080-00). All patients gave their written informed consent before enrolment.

\section{Immunoadsorption treatment}

IA was performed using the tryptophan-linked polyvinyl alcohol adsorber TR-350, after membrane plasma separation with the polyethylene plasma separator OP-05 W (Asahi Kasei Kuraray, Tokyo, Japan) in combination with the Octo Nova extracorporeal circuit technology (SW 4.30.2, front 4.30.0) (Diamed Medizintechnik, Cologne, Germany). The adsorber, plasma separator and tubing system were for single use only. Combined anticoagulation, with citrate and unfractionated heparin, was used for all treatments. The treated plasma volume was $2,500 \mathrm{~mL}$ plasma for all treatments of all patients. In total, five sessions were performed in each patient on alternate days. In case of complications or decrease of fibrinogen below $100 \mathrm{mg} / \mathrm{dL}$, treatment-free intervals were extended individually. Internal jugular veins were used for central vascular access with double lumen catheters in all patients.

\section{Baseline and follow-up visits}

All patients were followed up by a neurologist. Visits were performed at baseline (visit 0), after each IA treatment (visits 2 to 5 ) and after $30 \pm 5$ days (visit 6), $60 \pm 10$ days (visit 7) and $180 \pm 10$ days (visit 8 ). The neurological findings were assessed using the Expanded Disability Status Scale (EDSS) and the Incapacity Status Scale (ISS) [11-13]. Changes of visual acuity were monitored using standardized near vision types after correction of refractive error at each visit and confirmed by an ophthalmologist before and after IA, as well as at $180 \pm 10$ days. Visual evoked potentials were determined at baseline, after the last IA and $60 \pm 10$ days post-intervention with the Neuropack M1 (Nihon Koden, Surbiton, UK).

\section{Classification of side effects}

Side effects were defined as any unexpected or symptomatic event that had a possible, probable or definite causal relationship with IA treatment [14]. They were classified as mild, moderate or severe as described previously [15] with small modifications. Briefly, mild side effects included those of transient nature with little or no clinical significance and without any temporary break of the procedure. Side effects that required medical intervention but were not life-threatening were classified as moderate. Unstable and life-threatening events requiring termination of the procedure were classified as severe.

\section{Clinical chemistry}

All laboratory parameters were measured by standard methods. The complement components $\mathrm{C} 3 \mathrm{c}$ and $\mathrm{C} 4$ as well as the immunoglobulins G (IgG), A (IgA) and M (IgM) were measured by nephelometry (Behring Nephelometer II Analyzer, Germany). Soluble interleukin-2 receptor (sIL-2R) was detected on an immulite system (Siemens, Germany).

\section{Identification of immunoadsorption column-binding proteins by elution and proteomics}

Immusorba TR-350 column-binding proteins were eluted after the first IA treatment in five of eleven patients. Prior to elution, the column was washed with PBS buffer. The protein elution was carried out as following: PBS-washing step was followed by a three-step elution protocol using solution A (100 mM sodium acetate, $1 \mathrm{M} \mathrm{NaCl}, \mathrm{pH} 5)$, solution B (20 mM Tris-HCl, $1 \mathrm{M} \mathrm{NaCl}, \mathrm{pH} 8.5)$ and solution C (20\% acetonitril in double diluted $\mathrm{H} 2 \mathrm{O})$. Proteins eluted from all three steps were pooled together and aliquots of $10 \mathrm{~mL}$ were used for protein precipitation, protein estimation and two-dimensional gel electrophoresis.

Two-dimensional gel electrophoresis, protein visualization and image analysis, in-gel digestion, mass spectrometry analysis of the digestion products and protein identification using a database search were performed as 
described in detail in our previous publication [16]. For protein identification, qualitative criteria encompassed optimized mass accuracy ( $<50 \mathrm{ppm})$, minimal mass deviation (in the millidalton range) and highest possible probability score, which were assigned to each identified protein. Proteins identified by mass spectrometry are described qualitatively.

\section{Western blot analysis}

Western blot analyses were performed according to previously published data [17] with $20 \mu \mathrm{g}$ of plasma proteins. Equal loading was ascertained by Coomassie staining. For immunodetection of proteins, the following antibodies were used: rabbit polyclonal to human CD5 ligand (CD5L) and mouse monoclonal to human myelin basic protein (both Abcam, Cambridge, UK); and horseradish peroxidase-linked donkey anti-rabbit antibody (Amersham Biosciences, Freiburg, Germany). Results are expressed as mean \pm SD.

\section{Statistics}

Visit and response effects were studied by two-way repeated measures analysis of variance using the mixed procedure for the software SAS (version 9.1, SAS Institute). In this global analysis, $P<0.05$ indicated a significant effect. In the case of a significant effect at a particular visit, subsequent pairwise comparisons to baseline values were performed using one-way repeated measures analysis of variance to detect the point in time when the effect occurred. These comparisons were performed at Bonferroni-adjusted significance levels (related $P$-values are labeled with either Bonf. sig. (significant) or with Bonf. n.s. (non-significant)).

Smoothing splines with three degrees of freedom were fitted to mean values of each visit to illustrate the trends and the potential interactions between visits and response effects. Fitting was performed using the free software $\mathrm{R}$ (version 2.8, http://www.r-project.org).

Comparative statistical analyses of changes within-subject and within-treatment were performed using $t$-tests for paired samples in case of normal data and Mann-Whitney $U$-tests for non-normal data. Normality was checked by quantile-quantile plots. Again, test results with $P<0.05$ were considered significant.

\section{Results}

IA treatments were started after a mean time of 26.6 days after the initial symptoms and 10.8 days after the start of corticosteroid therapy. Each patient received at least two courses of corticosteroid therapy prior to IA therapy, with a mean cumulative dose of $10.9 \mathrm{~g}$ prednisolone equivalent but without a significant improvement, thus fulfilling the indication of therapeutic apheresis as adjunct treatment. An improvement of visual acuity up to 0.6 or more was achieved in eight of eleven patients (72.7\%) undergoing IA treatment (responder group). Two patients did not respond to therapy at any time point and one patient improved during IA therapy but deteriorated shortly after the end of IA therapy, associated with the incidence of a jugular venous thrombosis on the same side (non-responder group). The relevant data of patients' characteristics are shown in Table 1.

\section{Visual acuity}

Mean visual acuity of all patients significantly improved with a baseline value of $0.12 \pm 0.12$ before the start of IA, $0.36 \pm 0.33(P=0.0234)$ after the third IA and $0.72 \pm 0.38$ (day $180 \pm 10$ after IA; $P<0.001$ ). The effect was even more pronounced in the responder group. Mean visual acuity before start of IA was $0.15 \pm 0.12$ with an increase after the third IA to $0.47 \pm 0.32(P=0.0252$ Bonf. n.s. $)$ and even more up to $0.89 \pm 0.15$ ( $P<0.0001$ Bonf. sig.) at day $180 \pm 10$ after IA. By contrast, in the non-responder group, no significant changes of visual acuity were detectable. Results are summarized in Figure 1.

Relief of visual impairment inversely correlated with the time interval between the start of symptoms and the beginning of IA therapy $(\mathrm{r}=-0.539)$ with a trend $(P=0.08)$ favoring positive clinical response in early opposed to late IA initiation.

\section{Visual evoked potentials}

Before IA treatment, visual evoked potentials could not be identified in six of our patients with MS due to the severity of the optical neuritis. However, after treatment in four of these participants, potentials recovered at day 60. In five patients, the visual evoked potential amplitudes as well as latencies before and after IA could be compared. The mean amplitude was $2.31 \pm 2.57 \mathrm{mV}$ at baseline, $3.34 \pm 2.60 \mathrm{mV}$ after the last IA, and $5.69 \pm 1.76 \mathrm{mV}$ at day $60(P=0.37)$. Latencies did not show recovery in those five patients from baseline $(107.6 \pm 21.7 \mathrm{~ms})$ until day $60 \pm 10(112.3 \pm 17.1 \mathrm{~ms})$.

\section{Expanded disability status scale and incapacity status scale} The EDSS continuously improved in the responder group starting from $4.06 \pm 1.82$ at baseline to $3.44 \pm 2.38$ after the last IA to a minimum of $2.81 \pm 2.72$ at day $60 \pm 10 \quad(P=0.58)$, in contrast to the non-responder group who showed no changes. However, EDSS is clearly dominated by ambulation [12] and rather insensitive for visual dysfunction [13]. In parallel, ISS ameliorated in the responder group from $8.00 \pm 9.02$ at baseline with a continuous decrease to a minimum of $5.75 \pm 6.78$ at day $180 \pm 10(P=0.04)$, in contrast to no significant changes in the non-responder group. 
Table 1 Clinical baseline characteristics of the participants

\begin{tabular}{|c|c|c|c|}
\hline Parameter & Total $(n=11)$ & Responder $(n=8)$ & Non-responder $(n=3)$ \\
\hline \multicolumn{4}{|l|}{ Gender } \\
\hline Female & $7(64 \%)$ & $5(62 \%)$ & $2(67 \%)$ \\
\hline Male & $4(36 \%)$ & $3(38 \%)$ & $1(33 \%)$ \\
\hline \multirow[t]{2}{*}{ Age } & $33.6 \pm 10.5$ & $29.6 \pm 9.2$ & $44.3 \pm 8.0$ \\
\hline & (19.0 to 55.0$)$ & (19.0 to 47.0$)$ & (39.0 to 55.0$)$ \\
\hline \multirow[t]{2}{*}{ Body mass index } & $25.5 \pm 3.0$ & $22.9 \pm 2.6$ & $26.2 \pm 4.0$ \\
\hline & (20.1 to 30.7$)$ & (22.0 to 30.7$)$ & (20.1 to 25.7$)$ \\
\hline \multirow[t]{2}{*}{ Relapse rates in the past 12 months (median and range) } & 2 & 2 & 1 \\
\hline & (1 to 4$)$ & (1 to 4$)$ & (1 to 2$)$ \\
\hline \multirow[t]{2}{*}{ Baseline Expanded Disability Status Scale } & 4 & 3.5 & 4 \\
\hline & (2 to 7.5$)$ & (2 to 7.5$)$ & (3 to 4$)$ \\
\hline \multirow[t]{2}{*}{ Days after onset of relapse } & $26.6 \pm 14.6$ & $29.3 \pm 15.6$ & $19.3 \pm 10.1$ \\
\hline & (10.0 to 60.0) & $(10.0$ to 60.0$)$ & (10.0 to 30.0$)$ \\
\hline \multirow[t]{2}{*}{ Days after initiation of corticosteroid therapy } & $10.8 \pm 6.9$ & $12.3 \pm 6.6$ & $7.0 \pm 7.2$ \\
\hline & (1.0 to 20.0$)$ & (3.0 to 20.0 ) & (1.0 to 15.0$)$ \\
\hline \multirow[t]{2}{*}{ Cumulative dose of prednisolone equivalents (g) } & $9.5 \pm 3.7$ & $8.6 \pm 3.7$ & $12.0 \pm 2.6$ \\
\hline & $(4.0$ to 15.0$)$ & (4.0 to 15.0$)$ & (10.0 to 15.0$)$ \\
\hline \multirow[t]{2}{*}{ Duration of disease (years) } & $3.5 \pm 4.9$ & $5.7 \pm 2.9$ & $2.7 \pm 9.0$ \\
\hline & $(0.0$ to 16.0$)$ & (0 to 7.0$)$ & (0.0 to 16.0$)$ \\
\hline Initial disease modifying therapy & $3(27.3 \%)$ & $2(25 \%)$ & $1(33.3 \%)$ \\
\hline Interferon beta & $2(18.2 \%)$ & $2(25 \%)$ & $0(0 \%)$ \\
\hline Glatiramer acetate & $1(9.1 \%)$ & $0(0 \%)$ & $1(33.3 \%)$ \\
\hline
\end{tabular}

Descriptive values are shown either as absolute numbers (frequencies) or mean \pm standard deviation (minimum -maximum), except for baseline EDSS and relapse rates which are shown as medians and ranges.

\section{Side effects}

In total, 55 IA treatments were analyzed. Mild side effects were often reported and caused slight discomfort to the patients, such as coldness, cough, dizziness, headache, temporary hypertension, lacrimation, muscular cramps, nausea, palpations, pruritus, paresthesia, rhinorrhea, sweating, tinnitus or vomiting. They were transient and could be easily managed without therapy.

Ten moderate side effects were recorded during the IA phase. These included vascular access problems such as central venous catheter infection and jugular venous thrombosis as well as therapy-associated events that included chest pain, dyspnoe, transient hypotension and urticaria, which could be easily managed by approved medical interventions. Two patients developed febrile infections (common cold and phlebitis of a peripheral vein) within $24 \mathrm{~h}$ of IA, which were possibly related to short-term immune dysfunction caused by corticosteroid therapy and IA. No severe side effects occurred. Results are summarized in Table 2.

\section{Laboratory data}

In routine analyses, no significant changes were seen for the following values: partial thromboplastin time, hemoglobin, hematocrit, thrombocytes, sodium, calcium, creatinine, aspartate aminotransferase, alanine aminotransferase, alkaline phosphatase, gamma-glutamyltransferase, creatine kinase and C-reactive protein. Significant changes were detected for fibrinogen, leukocytes and total protein. Increased leukocyte counts at baseline were likely caused by corticosteroid therapy before starting IA.

Immunoglobulins IgA, IgG and IgM as well as complement components $\mathrm{C} 3 \mathrm{c}$ and $\mathrm{C} 4$ significantly decreased during IA therapy $(P<0.01)$. After the end of IA, however, these parameters gradually recovered and increased beyond baseline values (as shown for IgG and C3c in Figure 2A, B). We found a significant decrease of sIL-2R at a rate of $-35.4 \pm 20.7 \%(P=0.0054)$ after just one IA session in our patients with MS. Furthermore, timecourses of sIL-2R in responders and non-responders showed a significant difference $(P=0.03$; Figure $2 C)$. Sample dilution in the patients' circulation due to IA was excluded by laboratory follow-ups of hematocrit and albumin in serum.

\section{Proteomic data}

Our proteomic investigation allowed the identification of 41 proteins with a peptide mass fingerprinting-score 


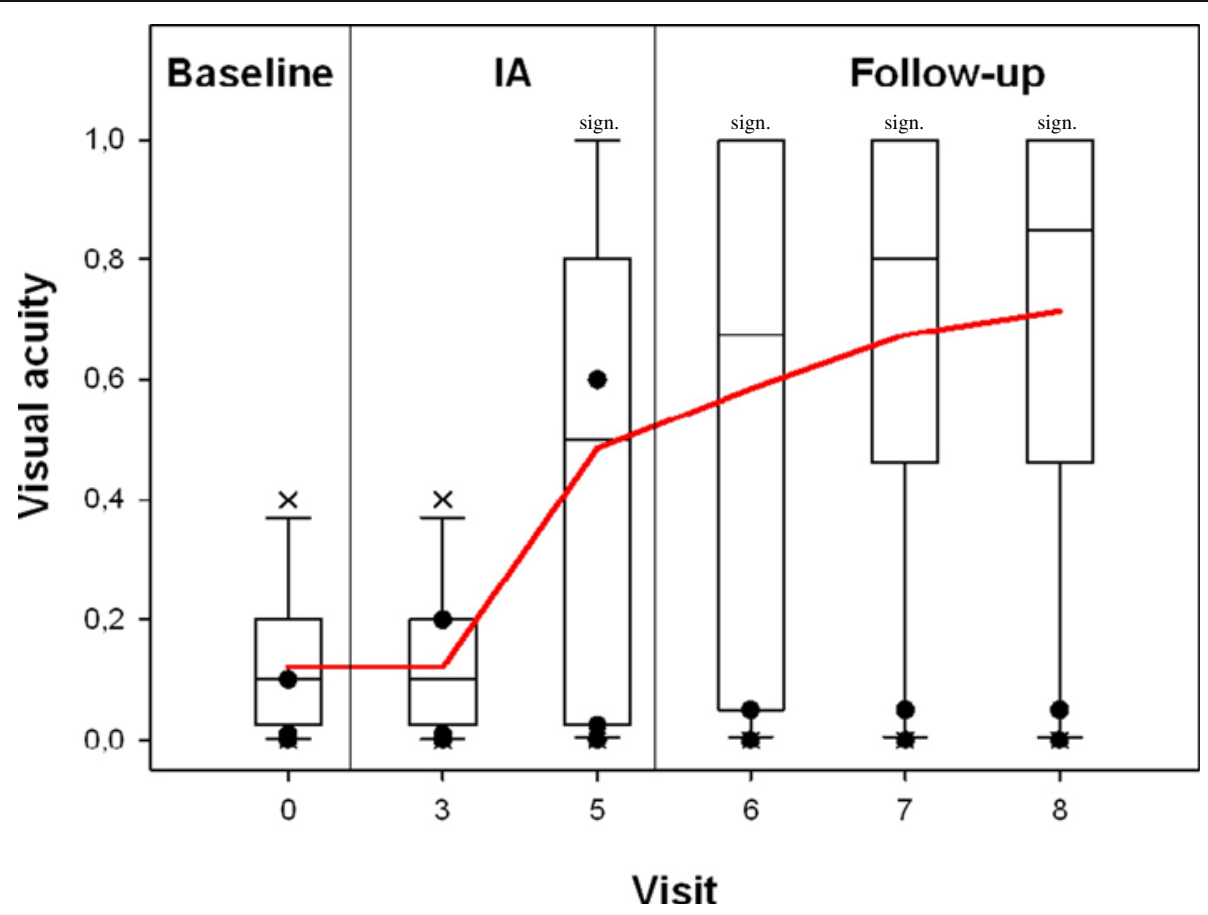

Figure 1 Time-course of visual acuities of the affected eyes assessed by standard charts in 11 patients with multiple sclerosis treated by immunoadsorption. Visual acuities were shown as box plots (outliers marked as X) at baseline (visit 0), after three IA therapies (visit 3), after five IA therapies (visit 5), after 30 days (visit 6), after 60 days (visit 7), and after 180 days (visit 8). Three patients did not show long-term improvement of visual acuity, they were termed non-responders in this study (shown as filled circles, partially overlapping each other). AE: affected eyes; sign.: significant (pairwise comparison to baseline).

$>65$ in eluates of IA columns. We could identify apolipoproteins, hemorheologically relevant proteins, immunologically relevant proteins, myelin-related proteins and others. A representative two-dimensional gel is

Table 2 Moderate adverse events occurring during immunoadsorption that were classified as being related to vascular access, the immunoadsorption procedure or immunosuppression

\begin{tabular}{|c|c|c|}
\hline & $\begin{array}{l}\text { Patients } \\
(n=11)\end{array}$ & $\begin{array}{l}\text { Immunoadsorption } \\
\text { therapies }(n=55)\end{array}$ \\
\hline \multicolumn{3}{|l|}{ Vascular access-related } \\
\hline $\begin{array}{l}\text { Central venous catheter exit site } \\
\text { infection }\end{array}$ & $1(9.1 \%)$ & $1(1.8 \%)$ \\
\hline Jugular vein thrombosis & $1(9.1 \%)$ & $1(1.8 \%)$ \\
\hline \multicolumn{3}{|c|}{ Side effects during immunoadsorption therapy } \\
\hline Chest pain & $1(9.1 \%)$ & $1(1.8 \%)$ \\
\hline Dyspnoe & $1(9.1 \%)$ & $1(1.8 \%)$ \\
\hline Transient hypotension & $4(36.5 \%)$ & $5(9.1 \%)$ \\
\hline Urticaria & $1(9.1 \%)$ & $1(1.8 \%)$ \\
\hline \multicolumn{3}{|c|}{$\begin{array}{l}\text { Putatively related to immunosuppression both by steroids and } \\
\text { immunoadsorption }\end{array}$} \\
\hline Febrile infection & $2(18.2 \%)$ & $2(3.6 \%)$ \\
\hline
\end{tabular}

shown in Figure $3 \mathrm{~A}$ and results are summarized in Table 3.

Amongst all identified proteins, soluble CD5L and the myelin basic protein (MBP) fragment were quantitatively analyzed in patients' sera by western blots using specific antibodies (Figure 3B). The baseline value was set to $100 \%$ and follow-up values were given in percent of baseline. Plasma MBP levels significantly decreased during the first IA session to $46.4 \pm 15.0 \%(P<0.001)$ and remained low even in the post-IA control at day $60 \pm 10$. In parallel, soluble CD5L (sCD5L) levels decreased to $50.5 \pm 15.0 \%(P<0.001)$ after the first IA and remained subsequently low. Time-courses of sCD5L and MBP are shown in Figure 3B.

\section{Discussion}

PE is an efficient treatment in acute central nervous system inflammatory demyelinating diseases [4], including severe optic neuritis, motor impairment or ataxia $[5,6]$ after steroid-refractory relapses, successful in about $40 \%$ to $50 \%$ of cases. Here, we report on the first prospective investigation of tryptophan-IA in 11 relapsing MS patients with optic neuritis refractory to corticosteroid pulses in an open prospective study. Overall, eight of 


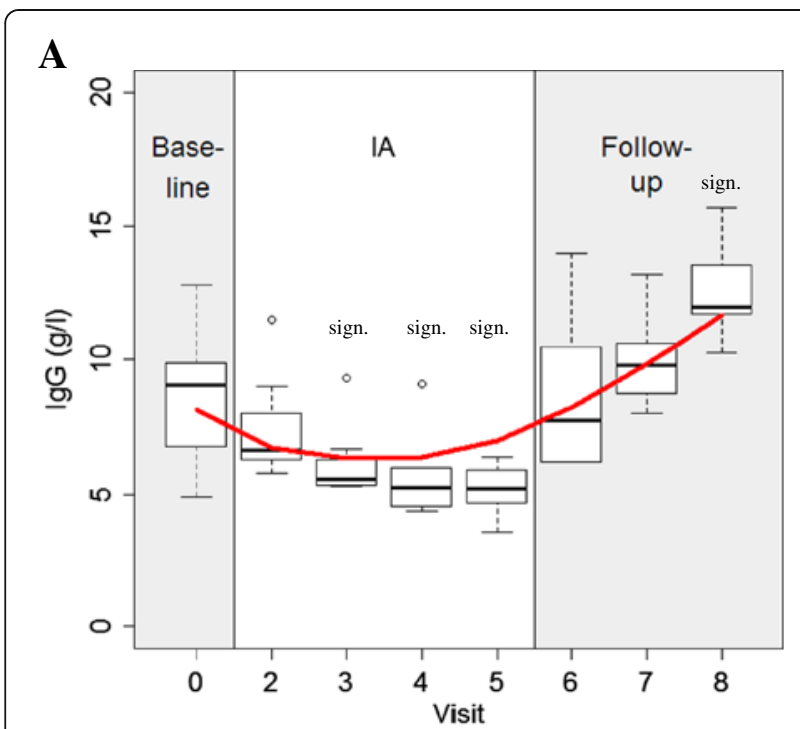

B

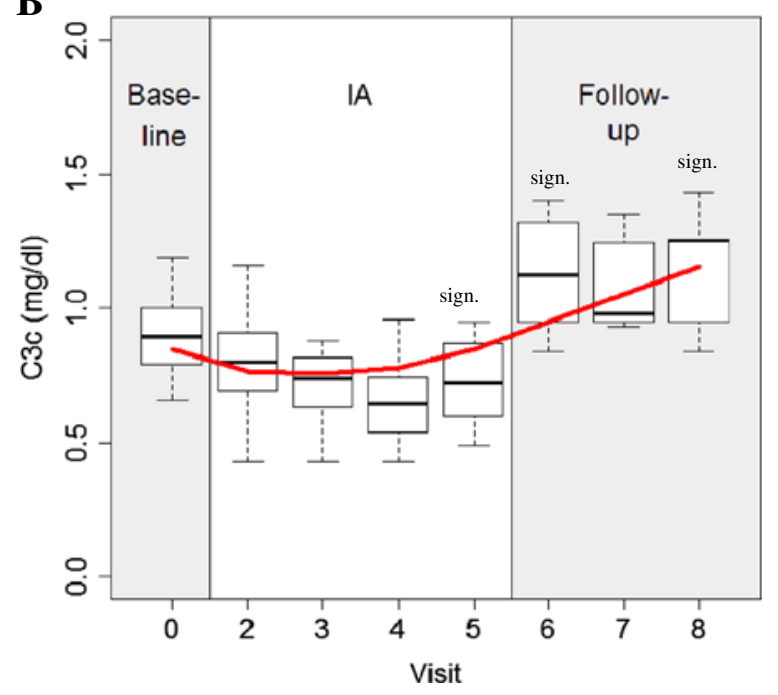

C

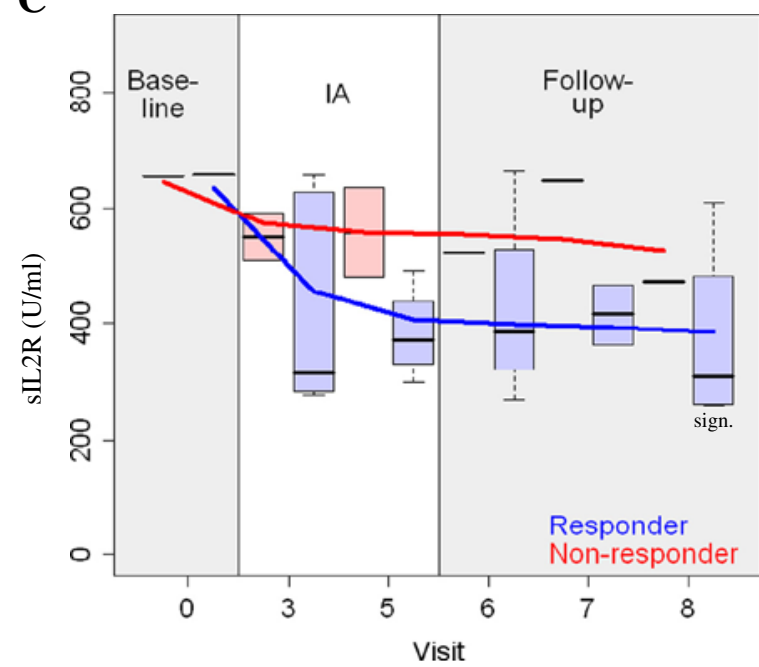

Figure $\mathbf{2}$ (See legend on next page.)
(See figure on previous page.)

Figure 2 Clinical chemistry. Time-courses of (A) lgG; (B) C3C and (C) SIL-2R. sIL-2R is shown in responders (blue) and non-responders (red). Box plots: sign: significant (pairwise comparison to baseline).

eleven patients (72.7\%) achieved a remission. One patient gradually improved but deteriorated again along with the development of jugular venous thrombosis, and two patients did not respond at all. The response to IA seems to be comparable to the best results achieved in PE series $[5,6]$ and to two very recent retrospective analyses of the effect of IA in steroid-refractory MS cases $[18,19]$. As in our own PE study [10], significant clinical improvement was seen after the third extracorporeal treatment session with a trend in favor of early IA initiation compared to delayed IA initiation. Our treatment protocol was limited to a total of five IA sessions. Additional experience showed that increasing the number of apheresis sessions did not correlate with further improvement of outcome (data not shown). This observation is in accord with results of IA in acute autoimmune neuropathies like Guillain-Barré Syndrome [20].

Most side effects were typical of any apheresis procedure using central venous lines as vascular access, but not characteristic of IA. Compared with the safety data from previously published PE studies [15,21], the incidence of mild adverse events was higher in our study, and moderate side effects were slightly more frequent. However, moderate side effects were almost level with our own study of neurological patients treated with PE [15]. Potential side effects of PE known to be related to the substitution of human plasma products were completely avoided [12].

Apart from clinical data, we analyzed possible therapeutic effects of IA with the help of proteomic analyses. Several relevant proteins, particularly fibrinogen and the immunoglobulins, were monitored. The decrease of fibrinogen is one limiting factor in the use of tryptophan-IA that makes regular controls necessary. Our protocol with five IA sessions on alternate days did not decrease fibrinogen to critical levels. Moreover, immunoglobulin depletion along with prior corticosteroid pulse therapy reflects a strong immunosuppression, which makes close controls of clinical and laboratory infection signs necessary. Previous investigations reported that the restoration of serum IgG levels until day 5 after IA does not result from increased antibody synthesis, but is probably related to changes of catabolism and immunoglobulin backflow [7]. Interestingly enough, we found a significant immunoglobulin increase beyond baseline values until day $180 \pm 10$ after the start of IA, suggesting additional mechanisms other than backflow alone.

Several mechanisms of PE action in neuroimmunological disorders have been described, such as a removal of 


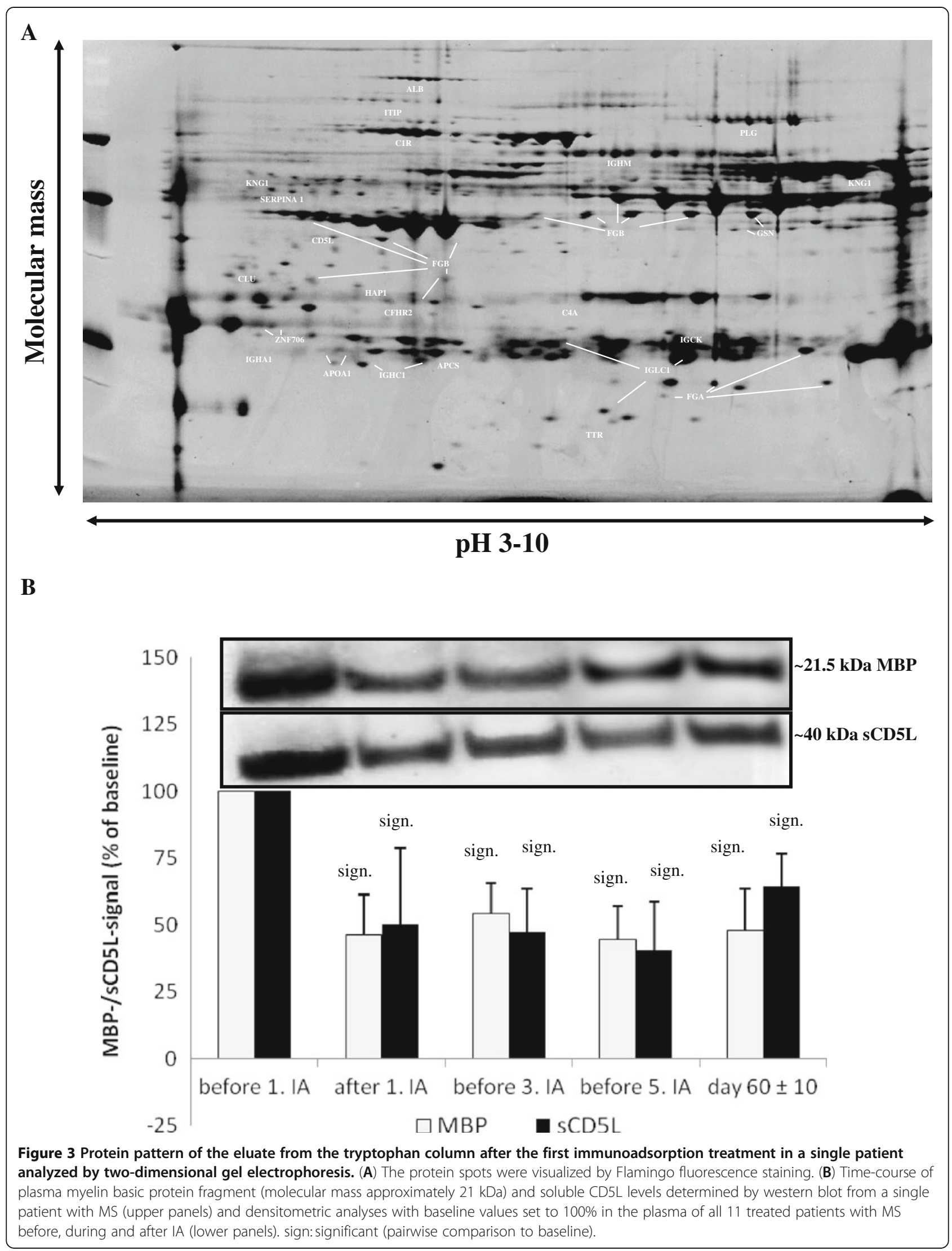


Table 3 List of identified proteins from immunoadsorption column elutes pooled from five patients with multiple sclerosis after the first immunoadsorption therapy

\begin{tabular}{|c|c|c|c|c|c|}
\hline Protein name & Gene name & UniProt & SwissProt & Nominal mass & PMF-score \\
\hline Alpha-1-antitrypsin & SERPINA1 & A1AT HUMAN & 57.5 & 46878 & 94 \\
\hline Apolipoprotein A-I & APOA1 & APOA1 HUMAN & 56.6 & 30759 & 152 \\
\hline Apolipoprotein A-IV & APOA4 & APOA4 HUMAN & 56.6 & 45371 & 67 \\
\hline CD5 antigen-like & CD5L & CD5L HUMAN & 56.8 & 39603 & 120 \\
\hline Cleavage stimulation factor, subunit, tau variant & CSTF2T & CSTFT HUMAN & 57.2 & 64624 & 57 \\
\hline Clusterin & CLU & CLUS HUMAN & 56.8 & 53031 & 160 \\
\hline Complement $\mathrm{C} 1 \mathrm{r}$ & C1R & C1R HUMAN & 57.5 & 81606 & 72 \\
\hline Complement factor I & CF1 & CFA1 HUMAN & 56.8 & 68072 & 86 \\
\hline Complement factor $\mathrm{H}$ & $\mathrm{CFH}$ & $\mathrm{CFAH}$ & 57.1 & 143680 & 61 \\
\hline Complement factor H-related protein 2 & CFHR2 & FHR2 HUMAN & 57.4 & 30631 & 60 \\
\hline Complement C4-A & $\mathrm{C} 4 \mathrm{~A}$ & CO4A & 57.4 & 192650 & 213 \\
\hline Fibrin alpha $\mathrm{C}$ term fragment & & gi 223057 & NCBI nr & 14443 & 85 \\
\hline Fibrinogen alpha chain & FGA & FIBA HUMAN & 57.1 & 95656 & 103 \\
\hline Fibrinogen beta chain & $\mathrm{FGB}$ & FIBB HUMAN & 57.1 & 56577 & 170 \\
\hline Fibrinogen gamma chain & FGG & FIBG HUMAN & 57.2 & 52106 & 146 \\
\hline Gelsolin & GSN & GELS HUMAN & 57.2 & 86043 & 95 \\
\hline Histidine-rich glycoprotein & HRG & HRG HUMAN & 57.0 & 60510 & 152 \\
\hline Huntingtin-associated protein 1 & HAP1 & HAP1 HUMAN & 57.5 & 76208 & 65 \\
\hline Kininogen 1 & KNG1 & KNG1 HUMAN & 56.8 & 72996 & 96 \\
\hline Transthyretin & $T T R$ & TTHY HUMAN & 56.6 & 15991 & 89 \\
\hline Immunoglobulin alpha- 1 chain $C$ region & IGHA1 & IGHA1 HUMAN & 57.4 & 37631 & 130 \\
\hline Immunoglobulin lamda chain $C$ region & IGLC1 & LAC HUMAN & 57.4 & 11230 & 218 \\
\hline Immunoglobulin mu chain $\mathrm{C}$ region & $\mathrm{IGHM}$ & IGHM HUMAN & 57.4 & 49960 & 90 \\
\hline Immunoglobulin kappa constant protein & & gi 49258112 & & 25915 & 78 \\
\hline Immunoglobulin kappa chain, $C$ region & IGCK & IGCK HUMAN & 57.2 & 11773 & 287 \\
\hline Immunoglobulin kappa light chain variable region & & gi 48475436 & NCBI nr & 21251 & 80 \\
\hline Immunglobulin kappa light chain VLJ region & & gi 21669479 & NCBI nr & 29086 & 76 \\
\hline Inter-alpha-trypsin inhibitor & ITIP & ITIH4 HUMAN & 57.5 & 103521 & 67 \\
\hline Monoclonal immunoglobulin M antibody light chain & & gi 41388186 & NCBI nr & 26008 & 65 \\
\hline Microtubule-actin crosslinking factor 1 & MACF & MACF1 & 57.0 & 623626 & 57 \\
\hline Mps one binder kinase activator-like2A & MOBKL2A & MOL2A & 57.0 & 25676 & 55 \\
\hline Myelin basic protein & MBP & MBP HUMAN & 56.6 & 33097 & 55 \\
\hline Malate dehydrogenase cytoplasmic & $\mathrm{MDH} 1$ & MDHC HUMAN & 56.6 & 36631 & 57 \\
\hline Plasminogen & PLG & PLMN HUMAN & 56.6 & 93247 & 89 \\
\hline Serum albumin & ALB & ALBU HUMAN & 57.5 & 71317 & 101 \\
\hline Serum amyloid P-component & APCS & SAMP HUMAN & 57.5 & 25485 & 68 \\
\hline Small ubiquitin-related modifier & SUMO1 & SUMO1 HUMAN & 57.2 & 11607 & 59 \\
\hline Transmembrane and tetratricopeptide repeat-containing protein 1 & TMTC1 & TMTC1 HUMAN & 57.2 & 88209 & 62 \\
\hline Zinc finger protein basonuclin-2 & BNC2 & BNC2 HUMAN & 57.2 & 1236677 & 62 \\
\hline Zinc fincer protein 706 & ZNF706 & ZN706 HUMAN & 57.4 & 8606 & 64 \\
\hline 39 S ribosomal protein L13 mitochondrial & MRPL13 & RM13 HUMAN & 57.0 & 20736 & 58 \\
\hline
\end{tabular}

Gene names, accession number and identification score are given. PMF: peptide mass finger printing. 
pathogenic autoantibodies, a redistribution of pathogens from the extravascular to the intravascular compartment, increased proliferation of immune cells, an enhanced production of immunoglobulins, a promotion of suppressor T-cell function, and a deviation of cytokine patterns redressing a disturbed T-helper type 1 and T-helper type 2 balance [3]. Although IA has been termed specific, several studies have demonstrated additional binding properties of ligands other than immunoglobulins alone [22,23]. According to our proteomics data, several proteins that are possibly involved in MS pathogenesis are removed from the plasma by IA, for example, transthyretin [24], serum amyloid P [24], complement factors [24], clusterin [24], gelsolin [24], kininogen-1 [24], MBP [25,26], CD5L [27] and immunoglobulins $[1,3,8]$. We confirmed a decrease of serum levels by IA in two of them, MBP and sCD5L. MBP-like material has been detected in several body fluids including cerebral spinal fluid and the urine of patients with MS [28]. Since MBP and other myelin proteins have been shown to be encephalitogenic in animal models of MS, they could drive the systemic autoimmune response in patients with MS. Other investigations have demonstrated the prevalence of MBP-specific memory B-cells in the peripheral blood of relapsing patients with remitting MS that might prime T-cells in lymphoid organs to migrate into the central nervous system and to elicit IFN- $\gamma$ secretion [25]. These data were further corroborated with the evidence of MBP-reactive T-cells among IL-2 expanded lymphocytes in patients with MS [26]. Thus, removal of MBP from the plasma by IA might interrupt these autoimmune mechanisms, although more research in this hypothesis is definitely needed.

sIL-2R, a marker of $\mathrm{T}_{\mathrm{H}} 1$ cell activation, is increased in the serum of patients with relapsing MS [14]. We induced a significant decrease of sIL-2R after IA in responders, but not in non-responders. Decreased sIL-2R levels might reflect the silencing of cellular autoimmune responses effective only in responders.

\section{Conclusions}

Our clinical results show a high clinical efficacy of tryptophan-IA comparable to PE in the treatment of MS relapses refractory to corticosteroids. Furthermore, our experimental data suggest several possible effects on MS pathogenesis: not only removal of immunoglobulins and complement from plasma, but also reduced levels of circulating autoantigens and regulatory proteins. We suggest that more prospective studies are needed to confirm and extend our results, to give new insights into this treatment approach, to optimize therapeutic IA protocols and, lastly, to investigate further therapeutic principles, for example, T-cell reactivity to MBP before and after IA.

\section{Abbreviations}

AE: Affected eye; CD5L: CD5 ligand; EDSS: Expanded Disability Status Scale; IA: Immunoadsorption; IFN: Interferon; Ig: Immunoglobulin; IL-2R: Interleukin-2 receptor; ISS: Incapacity Status Scale; KDa: kiloDalton; MBP: Myelin basic protein; MS: Multiple sclerosis; PBS: Phosphate-buffered saline; PE: Plasma exchange; PMF: Peptide mass fingerprinting; IIL-2R: Soluble interleukin-2 receptor.

\section{Competing interests}

This work was supported by a research grant of Diamed (Cologne, Germany) to MK and BK. The authors declare lecture fees and/or travel funding from Diamed (Cologne, Germany) to MK, BK and GAM. MK received research funds from Novartis, Germany, and RK from Asahi Kasei Kuraray Medical, Japan.

\section{Acknowledgment}

The authors thank the nursing staff from the medical intensive care unit 1022 as well as E. Brunst-Knoblich and A. Krüger (both Department of Nephrology \& Rheumatology, Georg-August-University Göttingen, Germany) for excellent technical support

\section{Author details}

'Department of Nephrology and Rheumatology, Georg-August-University Göttingen, Robert-Koch-Strasse 40, D-37075 Göttingen, Germany.

${ }^{2}$ Department of Neurology, Georg-August-University Göttingen, Robert-KochStrasse 40, D-37075 Göttingen, Germany. ${ }^{3}$ Department of Medical Statistics, Georg-August-University Göttingen, Robert-Koch-Strasse 40, D-37075 Göttingen, Germany. ${ }^{4}$ Apheresis Research Institute, Stadtwaldguertel 77 , 50935 Cologne, Germany.

\section{Authors' contributions}

MJK: design of the study, acquisition, analyses and interpretation of the data, drafting the manuscript, final approval. DT: acquisition and analyses of the data. MB: interpretation of the data, revising the manuscript. HD: analyses of the data. KJ: analyses of the data, revising the manuscript. DF: acquisition of the data, revising the manuscript. RK: design of the study, revising the manuscript. GAM: interpretation of the data, revising the manuscript. BK: design of the study, acquisition, analyses and interpretation of the data, drafting the manuscript, final approval. All authors read and approved the final manuscript.

Received: 24 October 2011 Accepted: 28 February 2012 Published: 26 April 2012

\section{References}

1. Lucchinetti CF, Bruck W, Parisi J, Scheithauer B, Rodriguez M, Lassmann $\mathrm{H}$ : Heterogeneity of multiple sclerosis lesions: implications for the pathogenesis of demyelination. Ann Neurol 2000, 47:707-717.

2. Reindl M, Linington C, Brehm U, Egg R, Dilitz E, Deisenhammer F, Poewe W, Berger T: Antibodies against the myelin oligodendrocyte glycoprotein and the myelin basic protein in multiple sclerosis and other neurological diseases: a comparative study. Brain 1999, 122:2047-2056.

3. Lehmann $H C$, Hartung HP, Hetzel GR, Stüve O, Kieseier BC: Plasma exchange in neuroimmunological disorders: Part 1: Rationale and treatment of inflammatory central nervous system disorders. Arch Neurol 2006, 63:930-935.

4. Weinshenker BG, O'Brien PC, Petterson TM, Noseworthy JH, Lucchinetti CF, Dodick DW, Pineda AA, Stevens LN, Rodriguez M: A randomized trial of plasma exchange in acute central nervous system inflammatory demyelinating disease. Ann Neurol 1999, 46:878-886.

5. Gold R, Hartung HP: Towards individualised multiple-sclerosis therapy. Lancet Neurol 2005, 4:693-694.

6. Ruprecht K, Klinker E, Dintelmann T, Rieckmann P, Gold R: Plasma exchange for severe optic neuritis: treatment of 10 patients. Neurology 2004, 63:1081-1083

7. Wiendl H, Toyka KV, Rieckmann P, Gold R, Hartung HP, Hohlfeld R, Multiple Sclerosis Therapy Consensus Group (MSTCG): Basic and escalating immunomodulatory treatments in multiple sclerosis: current therapeutic recommendations. J Neurol 2008, 255:1449-1463. 
8. Keegan M, Konig F, McClelland R, Brück W, Morales $Y$, Bitsch A, Panitch $H$, Lassmann $H$, Weinshenker B, Rodriguez M, Parisi J, Lucchinetti CF: Relation between humoral pathological changes in multiple sclerosis and response to therapeutic plasma exchange. Lancet 2005, 366:579-582.

9. Klingel R, Heibges R, Fassbender C: Plasma exchange and immunoadsorption for autoimmune neurologic diseases - current guidelines and future perspectives. Atheroscler Supp/ 2009 , 10:129-132.

10. Schilling $S$, Linker RA, König FB, Koziolek M, Bähr M, Müller GA, Paulus W, Gärtner J, Brück W, Chan A, Gold R: Plasma exchange therapy for steroid-unresponsive multiple sclerosis relapses: clinical experience with 16 patients. Nervenarzt 2006, 77:430-438.

11. Hetherington R: The Snellen chart as a test of visual acuity. Psychol Forsch 1954, 24:349-357.

12. Stegmayr B, Ptak J, Wikstroem B, Berlin G, Axelsson CG, Griskevicius A, Centoni $P$, Liumbruno G, Molfettini P, Audzijoniene J, Mokvist K, Nilsson B, Norda R, Knutson F, Ramlow W, Blaha M, Witt V, Evergren M, Tomaz J: World apheresis registry 2003-2007 data. Trans Apher Sci 2008, 39:247-254.

13. Kurtzke JF: Rating neurologic impairment in multiple sclerosis: an expanded disability scale (EDSS). Neurology 1983, 33:1444-1452.

14. Sivieri S, Ferrarini AM, Gallo P: Multiple sclerosis: IL-2 and sIL-2R levels in cerebrospinal fluid and serum. Review of literature and critical analysis of ELISA pitfalls. Mult Scler 1998, 4:7-11.

15. Bramlage C, Schröder C, Bramlage P, Ahrens K, Zapf A, Müller GA, Koziolek MJ: Predictors of complications of therapeutical plasma exchange. J Clin Apher 2009, 24:225-231.

16. Dihazi H, Koziolek MJ, Söllner T, Kahler E, Klingel R, Neuhoff R, Strutz F, Mueller GA: Protein adsorption during LDL-apheresis: proteomic analysis. Nephrol Dial Transplant 2008, 23:2925-2935.

17. Koziolek MJ, Müller GA, Zapf A, Patschan D, Koschnick S, Bramlage C, Vasko $\mathrm{R}$, Strutz F: Role of CX3C-chemokine CX3C-L/fractalkine expression in a model of slowly progressive renal failure. Nephrol Dial Transplant 2010, 25:684-698.

18. Trebst C, Bronzlik P, Kielstein JT, Schmidt BMW, Stangel M: Immunoadsorption therapy for steroid-unresponsive relapses in patients with multiple sclerosis. Blood Purif 2012, 33:1-6.

19. Mauch E, Zwanzger J, Hettich R, Fassbender C, Klingel R, Heigl F: [Immunoadsorption for steroid-unresponsive multiple sclerosis-relapses: clinical data of 14 patients]. Nervenarzt 2011, 82(12):1590-1595. In German.

20. Galldiks N, Dohmen C, Neveling M, Fink GR, Haupt WF: Selective immune adsorption treatment of severe Guillain-Barré-syndrome in the intensive care unit. Neurocrit Care 2009, 11:317-321.

21. Samtleben W, Blumenstein M, Liebl L, Gurland HJ: Membrane plasma separation for treatment of immunologically mediated diseases. Trans Am Soc Artif Intern Organs 1980, 26:12-16.

22. Oda S, Hirasawa H, Shiga H, Nakanishi K, Matsuda K, Nakamura M, Ikeda H, Sakai M: Cytokine adsorptive property of various adsorbents in immunoadsorption columns and a newly developed adsorbent: an in vitro study. Blood Purif 2004, 22:530-536.

23. Yoshida M, Tamura M, Yamada Y, Yamawaki N, Yamashita Y, Immusorba TR, Immusorba $\mathrm{PH}$ : Basics of design and features of functions. Ther Apher 1998, 2:185-192.

24. Rithidech KN, Honikel L, Milazzo M, Madigan D, Troxell R, Krupp LB: Protein expression profiles in pediatric multiple sclerosis: potential biomarkers. Mult Scler 2009, 15:455-464.

25. Harp CT, Ireland S, Davis LS, Remington G, Cassidy B, Cravens PD, Stuve O, Lovett-Racke AE, Eagar TN, Greenberg BM, Racke MK, Cowell LG, Karandikar NJ, Frohman EM, Monson NL: Memory B cells from a subset of treatment-naïve relapsing-remitting multiple sclerosis patients elicit CD4(+) T-cell proliferation and IFN- $\gamma$ production in response to myelin basic protein and myelin oligodendrocyte glycoprotein. Eur J Immunol 2010, 40:2942-2956.

26. Hellings N, Bare'e M, Verhoeven C, Beatrijs D'hooghe M, Medaer R, Bernard CCA, Raus J, Stinissen P: T-cell reactivity to multiple myelin antigens in multiple sclerosis patients and healthy controls. J Neurosci Res 2001, 63:290-302.

27. Axtell RC, Webb MS, Barnum SR, Raman C: Cutting edge: critical role for CD5 in experimental autoimmune encephalomyelitis: inhibition of engagement reverses disease in mice. J Immunol 2004, 173:2928-2932.
28. Whitaker JN: Myelin basic protein in cerebrospinal fluid and other body fluids. Mult Scler 1998, 4:16-21.

doi:10.1186/1742-2094-9-80

Cite this article as: Koziolek et al:: Immunoadsorption therapy in patients with multiple sclerosis with steroid-refractory optical neuritis. Journal of Neuroinflammation 2012 9:80.

\section{Submit your next manuscript to BioMed Central and take full advantage of:}

- Convenient online submission

- Thorough peer review

- No space constraints or color figure charges

- Immediate publication on acceptance

- Inclusion in PubMed, CAS, Scopus and Google Scholar

- Research which is freely available for redistribution 